\title{
Protection Against Hyperacute Xenograft Rejection of Transgenic Rat Hearts Expressing Human Decay Accelerating Factor (DAF) Transplanted into Primates
}

\author{
Béatrice Charreau, ${ }^{1}$ Séverine Ménoret, ${ }^{1}$ Laurent Tesson, ${ }^{1}$ \\ Agnès Azimzadeh, ${ }^{2}$ Maxime Audet, ${ }^{2}$ Philippe Wolf, ${ }^{2}$ \\ Richard Marquet, ${ }^{3}$ Caroline Verbakel, ${ }^{3}$ John Ijzermans, ${ }^{3}$ \\ Peter Cowan, ${ }^{4}$ Martin Pearse, ${ }^{4}$ Anthony d'Apice, ${ }^{4}$ \\ Jean-Paul Soulillou, ${ }^{1}$ and Ignacio Anegon ${ }^{1}$ \\ ${ }^{1}$ INSERM U437 "Immunointervention en Allo et Xénotransplantation" \\ and Institut de Transplantation et de Recherche en Transplantation, \\ Nantes, France \\ ${ }^{2}$ Fondation de Transplantation, Strasbourg, France \\ ${ }^{3}$ Erasmus Universiteit Rotterdam, Rotterdam, The Netherlands \\ ${ }^{4}$ Immunology Research Center, St. Vincent's Hospital, Fitzroy, \\ Victoria, Australia
}

Accepted July 17, 1999.

\begin{abstract}
Background: Production of transgenic pigs for multiple transgenes is part of a potential strategy to prevent immunological events involved in xenograft rejection. Use of a genetically engineerable rodent as a donor in primates could allow testing in vivo of the effects of different transgenes on controling xenograft rejection. As a first step in the development of a donor containing multiple transgenes, transgenic rats for human decay-accelerating factor (DAF) were used as heart donors to test their resistence against complement $(\mathrm{C})$-mediated rejection by non-human primates.

Materials and Methods: Transgenic rats were generated by using a construct containing the human DAF cDNA under the transcriptional control of the endothelial cell (EC)-specific human ICAM-2 promoter. DAF expression was evaluated by immunohistology and by FACS analysis of purified ECs. Resistance of transgenic hearts against $\mathrm{C}$-mediated damage was evaluated by ex vivo perfusion with human serum and by transplantation into cynomolgus monkeys.

Results: Immunohistological analysis of DAF expression in several organs from two transgenic lines

showed uniform expression on the endothelium of all blood vessels. ECs purified from transgenic hearts showed $50 \%$ DAF expression compared to human ECs and $>70 \%$ reduction of $\mathrm{C}$-dependent cell lysis compared to control rat ECs. Hemizygous transgenic hearts perfused with human serum showed normal function for $>60 \mathrm{~min}$ vs. $11.2 \pm 1.7 \mathrm{~min}$ in controls. Hemi- or homozygous transgenic hearts transplanted into cynomolgus monkeys showed longer survival (15.2 $\pm 7 \mathrm{~min}$ and $>4.5 \mathrm{hr}$, respectively) than controls $(5.5 \pm 1.4 \mathrm{~min})$. In contrast to hyperacutely rejected control hearts, rejected homozygous DAF hearts showed signs of acute vascular rejection (AVR) characterized by edema, hemorrhage, and an intense PMN infiltration.

Conclusions: We demonstrate that endothelialspecific DAF expression increased heart transplant survival in a rat-to-primate model of xenotransplantation. This will aid in the analysis of AVR and of new genes that may inhibit this form of rejection, thus helping to define strategies for the production of transgenic pigs.
\end{abstract}




\section{Introduction}

The use of porcine organs for clinical transplantation is an approach to overcoming the shortage of human organs. The first obstacle to xenotransplantation is the recipient's innate immune response which results in xenograft hyperacute rejection (HAR) (for review see refs. 1). Rejection of transplants performed between discordant species, such as pig to primates, involves the binding of preformed xenogeneic natural antibodies (XNA) directed to Gal $\alpha$-3Gal epitopes on the endothelial cell (EC) surface $(2,3)$. Interaction between XNA and their targets promotes complement $(\mathrm{C})$ activation, leading to graft endothelium injury and activation (4-7). Prevention of xenograft HAR has been successfuly achieved by either inhibition of XNA binding through depletion of XNA or reduction of Gal $\alpha 1-3 \mathrm{Gal}$ expression on ECs $(8,9)$, or by blockade of complement activation (10). Transgenic pigs expressing human complement regulatory proteins (CRPs), including decay-accelerating factor (DAF) and/or CD59, have been produced to avoid complement-mediated graft damage (11-13). Dramatic improvement of xenograft survival has been obtained using these transgenic transplants in the pig-to-primate model of xenotransplantation (14-16). These studies demonstrated that human DAF and/or CD59 expression on graft ECs, in association with antibody depletion and/or immunosuppressive regimen, efficiently overcome HAR. However, optimal transgene expression levels as well as its optimal tissue distribution remained to be determined.

Since xenograft HAR can be circumvented by the use of transgenic animals for CRPs, humoral and cell-mediated processes involved in delayed xenograft rejection or AVR may be further controlled by the production of transgenic animals expressing other transgenes acting on these processes in addition to CRPs. To this end, prior to the generation of transgenic pigs, production of transgenic small laboratory animals is needed. These animals would not only serve as tools for analysis of DNA construction for transgenesis but more impor-

Address correspondence and reprint requests to: Dr. Béatrice Charreau, INSERM U437 and Institut de Transplantation et de Recherche en Transplantation, 30 Boulevard Jean Monnet, 44093 Nantes Cedex, France. Phone: 33-240-08-74-10; Fax: 33-2-40-08-74-11; E-mail: charreau@nantes.inserm.fr tantly would help us investigate in vivo the biological relevance of transgene expression on xenograft rejection. In addition, models bearing close resemblance to the pig-to-primate one may be particularly useful. In this regard, although transgenic mice have been used to define the expression of DNA construction $(17,18)$ and their organs perfused ex vivo, their reduced size make it nearly impossible to graft their organs in primates.

We previously established an in vivo experimental model for xenotransplantation using the rat as organ donor and an old World primate (cynomolgus) as recipient. In this ratto-primate combination, HAR occurred $5 \mathrm{~min}$ after vascular anastomosis, with features mimicking HAR (19) and EC injury (7) observed in the pig-to-primate model. In addition, we demonstrated that, in vitro, human DAF and CD59 efficiently protect transfected xenogeneic rat ECs against cell lysis mediated by nonhuman primate sera (20). In the present study, we investigated the ability of human DAF expressed by the endothelium to delay HAR by producing transgenic rats for the human DAF. Endothelium-specific transgene expression was analyzed by immunohistochemistry on tissue sections and quantitated in vitro by isolation of cardiac ECs followed by flow cytometry. Ex vivo perfusion of transgenic hearts with human serum demonstrated the ability of human DAF expression to prevent XNA and Cmediated organ damage. Correlation between the DAF expression level on graft ECs and graft survival time was documented following cardiac heterotopic transplantation using hemizygous and homozygous transgenic rats as donors and unmodified cynomolgus as recipients. Histopathological features of acute vascular rejection (AVR) of DAF-expressing cardiac xenograft were characterized by polymorphonuclear leukocytes (PMN) infiltration, intersticial edema, and focal myocardium necrosis.

\section{Materials and Methods}

\section{Generation of Transgenic Rats}

The plasmid expression vector phICAM2DAF (Fig. 1A) contains a $1.9 \mathrm{~kb} E c o$ RI fragment of the human CD55 cDNA, $334 \mathrm{pb}$ of the promoter region of the human intercellular adhesion molecule 2 (ICAM2) gene (nucleotides -292 to +44 ), a universal intron, and the SV40 polyA, as previously described (21). The $3.12 \mathrm{~kb} \mathrm{KpnI-SacI}$ 


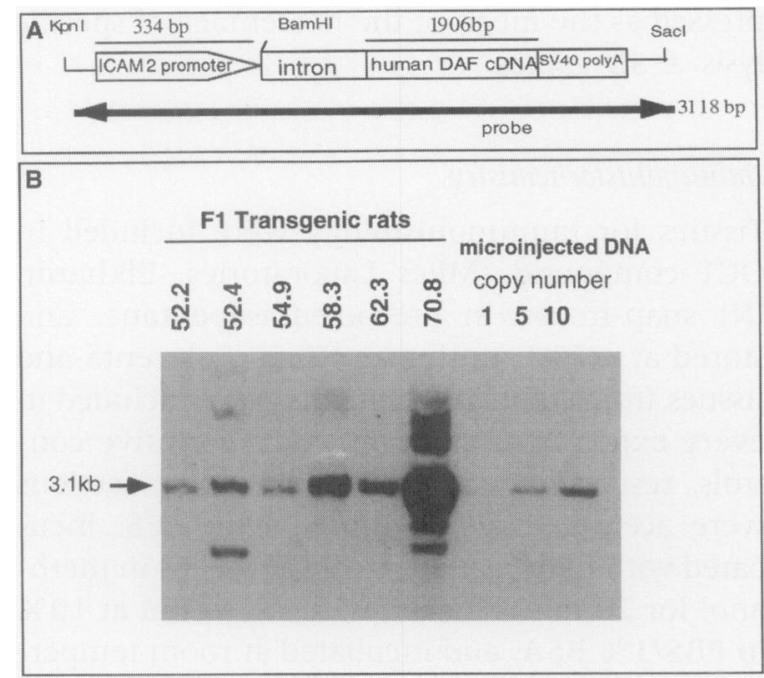

Fig. 1. Analysis of transgene integration in transgenic rats. (A) Design of ICAM2DAF cDNA construct used for microinjection (not drawn to scale). (B) Southern blot from transgenic rats $\left(\mathrm{DAF}^{+/-}\right)$. Genomic DNA (10 $\left.\mu \mathrm{g}\right)$ was digested by BamHI, separated through $1 \%$ agarose gel electrophoresis, and blotted. Known copy numbers of the microinjected fragment diluted into genomic DNA from a nontransgenic rat were used as controls. Blot was hybridized with a ${ }^{\alpha 32} \mathrm{P}$-dCTP labeled cDNA probe encoding the microinjected cDNA sequences (3.1 kb). Bam HI releases a $3.1 \mathrm{~kb}$ fragment (arrow).

fragment was excised from phICAM2DAF and isolated by electrophoresis through a $1 \%$ agarose gel, electroeluted, purified through an Elutip column (Schleicher \& Schull, Keene, NH), and diluted to a concentration of $2 \mathrm{ng} / \mathrm{ml}$ in $5 \mathrm{mM}$ Tris- $\mathrm{HCl}$ and $0.1 \mathrm{mM}$ EDTA, $\mathrm{pH}$ 7.4. Fertilized rat eggs were recovered from superovulated Sprague-Dawley (SD) females mated with SD males (Charles River, Saint-Aubin-Les-Elbeuf, France). DNA solution ( $2 \mathrm{ng} / \mu \mathrm{l})$ was microinjected into the male pronucleus and transferred into both oviducts of day 0 pseudopregnant SD females as previously described (22).

Identification of the transgenic founder animals and their progeny was determined by polymerase chain reaction (PCR) analysis of genomic DNA obtained from tail biopsies digested with proteinase $\mathrm{K}$ in a total volume of $450 \mu \mathrm{l}$ for $16 \mathrm{hr}$ at $56^{\circ} \mathrm{C}$ and then confirmed by Southern blots. PCR analysis was performed on $2 \mu \mathrm{l}$ of the DNA solution diluted to $1 / 20$ with oligonucleotides specific for human DAF (sense: 5'GAC GCT AGT AAT CAT GGG CT3'; antisense: 5'TAG GAA AGG AAT CAC TCT CA3') for 30 cycles of amplification $\left(94^{\circ} \mathrm{C}\right.$ for $30 \mathrm{sec} ; 50^{\circ} \mathrm{C}$ for $30 \mathrm{sec} ; 72^{\circ} \mathrm{C}$ for $30 \mathrm{sec}$ ). For Southern blot analysis, $10 \mu \mathrm{g}$ of DNA was digested by BamHI, fractionated on $1 \%$ agarose gel, and alkali blotted. Hybridization was carried out with a ${ }^{32 \alpha} \mathrm{P}$-dCTP-radiolabeled 3.12 kb KpnI-SacI fragment of the phICAM2DAF construct used for microinjection as a probe (probe showed in Fig. 1A). Determination of transgene copy number in genomic DNA from progeny and discrimination between hemizygous and homozygous rats was evaluated by probing a Southern blot of BamHI-digested tail DNA and known quantities of the microinjected fragment diluted in genomic DNA, followed by PhosphorImager analysis (Molecular Dynamics, Sunnyvale, CA).

\section{EC Isolation and Culture}

ECs were isolated from heart and lung. Briefly, tissues collected on transgenic or nontransgenic animals were cut in small pieces and then incubated with $1.8 \mathrm{U} / \mathrm{ml}$ Dispase II (Boehringer Mannheim, Mannheim, Germany), $0.5 \mathrm{mg} / \mathrm{ml}$ DNase I (Boehringer Mannheim) and 1\% fetal calf serum (FCS) (Gibco BRL, Grand Island, NY) in Hank's buffered salt solution (HBSS) (Gibco $\mathrm{BRL}$ ) for $4 \mathrm{hr}$ at $37^{\circ} \mathrm{C}$. Biopsies were then incubated overnight in $2 \mathrm{IU} / \mathrm{ml}$ collagenase B (Boehringer Mannheim) at $4^{\circ} \mathrm{C}$. Cell suspension was washed three times in HBSS medium before being plated on gelatin-coated tissue culture dishes (Nunc, Napervile, IL). DAF-expressing porcine endothelial cells were isolated from transgenic pig aortas by collagenase digestion $(1 \mathrm{U} / \mathrm{ml}$; Boehringer Mannheim). Human umbilical vein endothelial cells (HUVEC) were prepared as previously described (23). Purity of EC preparations was checked by the uptake of Dil-Ac-LDL as previously described (20). Endothelial cells were cultured in Dulbecco's modified Eagle's medium (DMEM) containing $4.5 \mathrm{~g} /$ liter glucose (Gibco BRL) and supplemented with $20 \%$ serum [fetal calf serum (FCS) (Gibco BRL) and human serum for rat ECs and HUVECs, respectively], $5 \mathrm{IU} / \mathrm{ml}$ heparin, $200 \mu \mathrm{g} / \mathrm{ml}$ Endothelial Cell Growth Supplement (Collaborative Biomedical Research, Becton Dickinson, San Jose, CA), $2 \mathrm{mM}$ glutamine, $100 \mathrm{U} / \mathrm{ml}$ penicillin, and $100 \mu \mathrm{g} / \mathrm{ml}$ streptomycin (Gibco BRL). Cells were analyzed between passages 1 and 4 .

\section{FACS Analysis}

Endothelial cells (1-2 $\times 10^{5}$ cells/sample) were suspended with trypsin-EDTA (Gibco BRL), 
washed twice with phosphate-buffered saline (PBS) containing $1 \%$ bovine serum albumin (BSA) and $0.01 \% \mathrm{NaN}_{3}$, and then incubated on ice for $30 \mathrm{~min}$ with a saturating concentration of the relevant monoclonal antibody (MAb). This step was followed by three washes in cold $1 \%$ BSA $/ 0.1 \% \mathrm{NaN}_{3} / \mathrm{PBS}$. Staining with a FITC-labeled-F( $\left(a^{\prime}\right) 2$ fragment of either goat antimouse, sheep anti-rabbit, or mouse anti-human immunoglobulin G (IgG) or IgM (Jackson Lab., West Grove, PA) was performed at $4^{\circ} \mathrm{C}$ for 30 min. Three washes in $1 \%$ BSA/0.1\% $\mathrm{NaN}_{3} / \mathrm{PBS}$ were performed before fixing the cells in $1 \%$ paraformaldehyde in PBS. The following antibodies were used in this study: rabbit polyclonal serum anti-human von Willebrand factor (vWf) (Dako, Trappes, France), anti-human DAF (1H4) MAb (CRTS, Nantes, France), and anti-rat ICAM-1 MAb (Seikagaku America, Rockville, $\mathrm{MD)}$. For analysis of human Ig binding on rat ECs, cells were incubated with purified human anti-Gal $\alpha \mathrm{l}-3 \mathrm{Gal}$ antibodies $(10 \mu \mathrm{g} / \mathrm{ml}, 100 \mu \mathrm{l} /$ $2 \times 10^{5}$ cells) for $30 \mathrm{~min}$ at $4^{\circ} \mathrm{C}$, washed, and then incubated with specific FITC-labeled goat $\mathrm{F}\left(\mathrm{ab}^{\prime}\right) 2$ anti-human IgM $(\mathrm{Fc} \mu)$ or IgG (Fc $\left.\gamma\right)$ (Jackson Laboratories) antibodies.

Analysis of complement activation was investigated following incubation of rat ECs with human serum (dilution 1:10) in DMEM medium for $30 \mathrm{~min}$ at $37^{\circ} \mathrm{C}$. Immunostaining was performed using FITC-labeled anti-human factor B, C3, C4 MAb (Atlantic Antibodies, Stillwater, $\mathrm{MN}$ ) and an anti-human C5b-9 polyclonal serum as first antibodies revealed using FITC-labeled goat anti-rabbit IgG or IgM (Jackson Lab). Fluorescence was measured on 10,000 cells per sample using a FACScalibur (Becton Dickinson). Data are depicted in histograms plotting mean fluorescence intensity (MFI) on a log scale ( $\mathrm{x}$ axis) versus cell number ( $y$-axis).

\section{Complement-dependent Cytotoxicity Assay}

Cells were labeled with ${ }^{51} \mathrm{Cr}\left(50 \mu \mathrm{Ci} / 1 \times 10^{6}\right.$ cells) for $1 \mathrm{hr}$ at $37^{\circ} \mathrm{C}$. Protection of DAF-expressing cells was assessed by incubating $51 \mathrm{Cr}$ labeled rat ECs $\left(2 \times 10^{4}\right.$ cells) with cynomolgus primate serum (as a source of xenogeneic antibodies and complement) (100 $\mu$ l, dilution 1:4 to 1:16) for $4 \mathrm{hr}$ at $37^{\circ} \mathrm{C}$. Chromium release was measured in supernatants, and the percentage of cell lysis was calculated by the following formula: (experimental cpm - cpm medium only)/(100\% lysis cpm - cpm medium only). All experiments were done in triplicate, and the results are ex- pressed as the mean of the percentage of specific lysis $\pm \mathrm{SD}$ values.

\section{Immunohistochemistry}

Tissues for immunohistology were included in OCT compound (Miles Laboratories, Elkhardt, IN) snap-frozen in precooled isopentane, and stored at $-70^{\circ} \mathrm{C}$ until use. Human placenta and tissues from nontransgenic rats were included in every experiment as positive and negative controls, respectively. Frozen $5-\mu \mathrm{m}$ tissue sections were acetone fixed, hydrated with PBS, incubated with hydrogen peroxide at $0.15 \%$ in methanol for $20 \mathrm{~min}$, blocked with rat serum at $10 \%$ in $\mathrm{PBS} / 1 \% \mathrm{BSA}$, and incubated at room temperature for $60 \mathrm{~min}$ with $\mathrm{MAb}$ at $10 \mu \mathrm{g} / \mathrm{ml}$. Tissue sections were then incubated with biotin-conjugated horse anti-mouse IgG absorbed with rat serum proteins (Vector, Burlingame, CA) followed by horseradish peroxidase streptavidin (Vector) and developed with very intense purple (VIP kit, Vector). Slides were then counter stained with hematoxilin and mounted with glycerol. The following antibodies were used in this study: anti-rabbit vWf, anti-human DAF (1H4), and purified human anti-Gal $\alpha 1-3 \mathrm{Gal}$ antibody. Negative controls were performed using an isotype-matched irrelevant MAb (3G8). Semiquantitative analysis of DAF expression on endothelium was obtained by visual evaluation of the intensity of specific staining, which was ranked from 0 to $4(0$, no staining; 1 , low intensity; 2, medium intensity; 3, high intensity; 4, very high intensity). Cardiac xenografts were analyzed for complement and xenogeneic antibody binding by immunofluorescence. Cynomolgus Ig binding was revealed through FITC-labeled goat $\mathrm{F}\left(\mathrm{ab}^{\prime}\right) 2$ anti-human IgM (Fc $\mu$ ) or IgG (Fcy) (Jackson Laboratories) antibodies.

\section{Ex Vivo Perfusion of Transgenic Hearts with Human Serum}

Rats were anesthetized with ether and the hearts were removed rapidly. A 22-gauge in-dwelling cannula (Vasocan, Braun Melsungen, Germany) was introduced into the aorta and secured with a ligature. Using a syringe, the hearts were perfused immediately with oxygenated perfusate and subsequently connected to the Langendorff circuit. The circuit was oxygenated by continuous gassing with a mixture of $95 \% \mathrm{O}_{2}$ to $5 \%$ $\mathrm{CO}_{2}$. The perfusate was kept at $37^{\circ} \mathrm{C}$ by continuous heated water. The largest reservoir was 
filled with a solution containing $30 \%$ Haemaccel (Behring, Marburg, Germany) in Krebs-Henseleit buffer (in $\mathrm{mM}$ : $\mathrm{NaCl} 118.0, \mathrm{KCl} 4.7, \mathrm{CaCl}_{2}$ 2.52, $\mathrm{MgSO}_{4}$ 1.66, $\mathrm{NaHCO}_{3} 24.88, \mathrm{KH}_{2} \mathrm{PO}_{4} 1.18$, glucose 5.55 , sodium pyruvate 2.0 ). The small reservoir was filled with $15 \%$ human serum (a pool of 20 human type-A plasma) diluted with the solution from the large reservoir. Before serum perfusion, hearts were allowed to stabilize by perfusing them with the Krebs-HenseleitHaemaccel solution for $10 \mathrm{~min}$. The hearts were monitored continuously for heart rate, apex amplitude, and flow by means of multichannel registration. Duration of heart function was defined as the time between the start of serum perfusion and complete cessation of heart beat. Decomplementation was performed by heating the serum for $1 \mathrm{hr}$ at $56^{\circ} \mathrm{C}$. Hemizygous rats $(n=5)$ from the transgenic line 52.2 were tested and compared to wild-type (WT) rats $(n=5)$.

\section{Cardiac Xenografts into Primates}

Transgenic and WT Sprague-Dawley rats of 300$400 \mathrm{~g}$ body weight were used as donors and cynomolgus monkeys of $6-9 \mathrm{~kg}$ body weight were used as recipients. Heterotopic heart xenotransplantation was performed as previously described (19). To compare graft survival of heart from hemizygous and homozygous transgenics, one of each organ was concomitantly grafted onto the same recipient in each femoral vessel. Xenograft survival was determined by visual examination and palpation of xenogeneic heart beating. Histological analysis of rejected xenografts was performed on paraffin-embedded sections $(5 \mu \mathrm{m})$ stained with hematoxilin-eosin.

\section{Statistical Analysis}

All data (mean \pm SD) were analyzed using the Student's $t$-test, with $p<0.05$ being the level of significance.

\section{Results}

Production of Transgenic Rats for Human DAF and Transgene Integration Analysis

A total of 754 eggs was microinjected and subsequently reimplanted into 37 pseudopregnant foster mothers, 27 of whom gave birth to 145 rats. Transgene integration was first detected by PCR in six founder animals and then confirmed by Southern blot performed on genomic
DNA. Figure 1 shows the presence of a human DAF sequence in a major restriction fragment of $3.1 \mathrm{~kb}$ in these transgenic lines as determined by hybridizing Southern blots, using the ICAM2DAF cDNA construct as a probe. The hybridization pattern revealed that multiple copy numbers of transgenes, in a head-to-tail orientation, had been integrated in all of these animals within one integration site, with the exception of line 70.8. Evaluation was done by comparing the size and intensity of hybridized fragment with known amounts of the microinjected fragment. High copy numbers (10 to $100)$ were observed in transgenic rats 58.3, 62.3 , and 70.8 . The transgene was transmitted to about $50 \%$ of the progeny for founders 52.2 , $52.4,62.3$, and $70.8(37 \%, 37 \%, 50 \%$, and $50 \%$, respectively). In contrast, a low transmission rate of the transgene to the offspring was obtained with founders $54.9(8 \%)$ and 58.3 $(<3 \%)$, which suggests that the germ-line in these founders was mosaic for DAF integration.

\section{Tissue Expression of Human DAF in Transgenic Rats}

Expression of human DAF was investigated in several organs from transgenic rats, including heart, kidney, liver, and lung, and on lymphoid organs (thymus, spleen). Cryosections of tissues were analyzed by immunohistology with an anti-human DAF MAb and compared to tissues from nontransgenic control rats. Consistent levels of DAF were detectable in tissues on progeny from lines 52.2 and 62.3. A low level of DAF was observed on line $\mathbf{5 2 . 4}$ while no expression was obtained for the lines 54.9, 58.3, and 70.8. For both transgenic lines (52.2 and 62.3), ECs expressing the transgene were detected in all analyzed tissues, including heart, kidney, lung, and liver. In these organs, DAF expression was restricted to both vascular (large and medium size vessels) and capillar endothelium as determined by comparison with the pattern of staining obtained with an antibody directed to vWf (data not shown). All tissues analyzed from rat $\mathbf{5 2 . 2}$ showed higher expression of human DAF than those in corresponding organs from line 62.3. The nontransgenic (WT) control rat showed no staining of the tissues analyzed. Specific stainings for human DAF obtained in heart and kidney from an hemizygous transgenic rat (line 52.2) are presented in Figure 2. Confirmation of endothelium-specific DAF expression in transgenic 


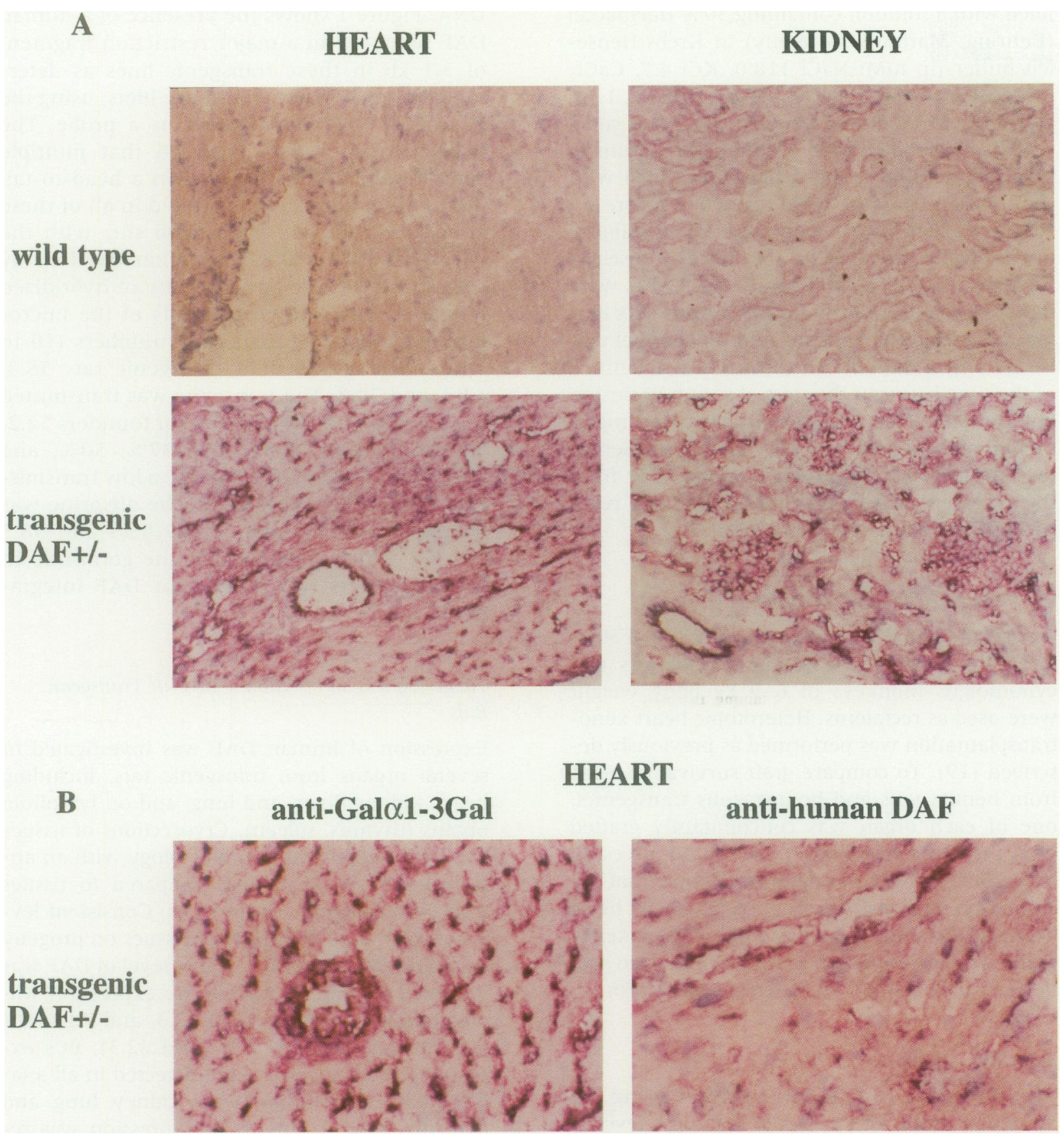

Fig. 2. Expression of human DAF in transgenic rat tissues. Frozen sections $(5 \mu \mathrm{m})$ from transgenic (hemizygous $\mathrm{DAF}^{+1-}$ rat from line 52.2) or wildtype (WT) rat tissues were fixed in acetone for 10 min at room temperature, air dried, and stained using an indirect immunoperoxidase technique. (A) Immunostaining of serial tissue sections from kidney or heart was performed with an anti-human

heart was achieved by comparison with the pattern of staining obtained with purified human anti-Gal $\alpha$ l-3Gal (7). Relative levels of DAF ex-
DAF MAb as first antibody (magnification, $\times 200$ ). Negative controls were performed using an isotypematched irrelevant MAb (data not shown). (B) Immunostaining of $\mathrm{DAF}^{+/-}$transgenic rat heart with human anti-Gal $\alpha 1-3 \mathrm{Gal}$ antibodies or an anti-human DAF MAb as first antibody followed by staining with a peroxidase-labeled anti-human or anti-mouse $\mathrm{Ig}$, respectively (magnification, $\times 400$ ).

pression on cells from these tissues were compared and are summarized on Figure 3. Expression was seen in a very small fraction of spleen 

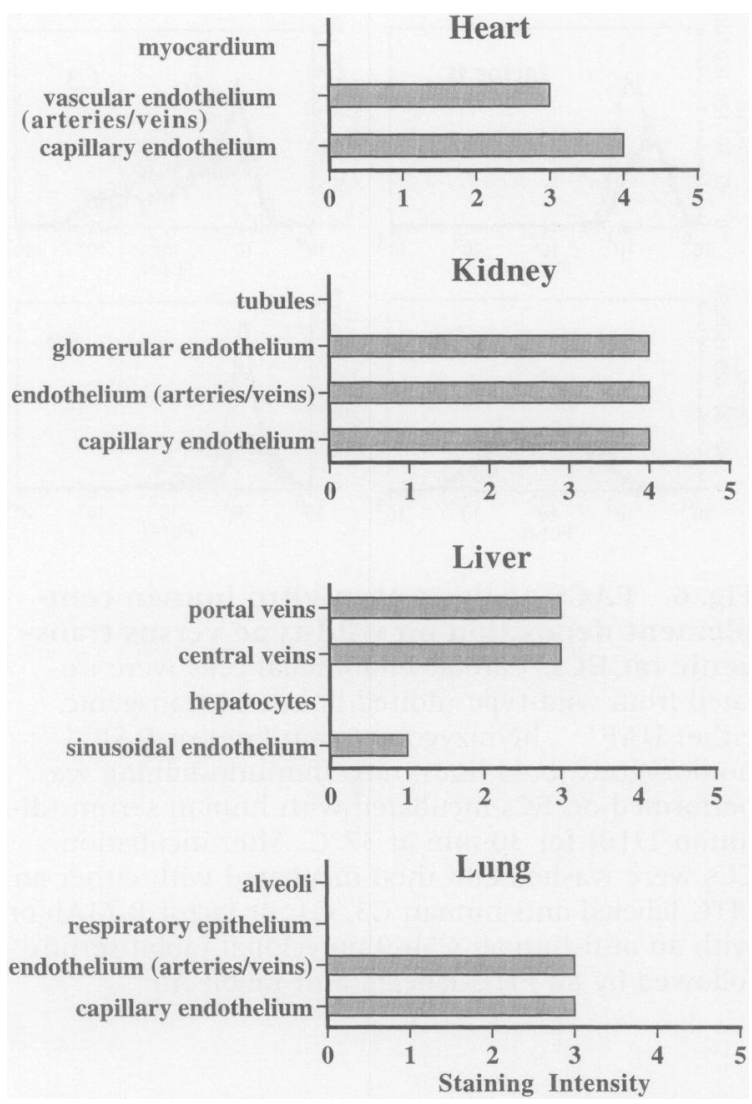

Fig. 3. Semiquantitative analysis of DAF endothelial expression in tissues from transgenic line 52.2. DAF expression in ECs from different tissues was determined by immunochemistry on cryosections as described in Materials and Methods. Results are expressed according to the intensity of specific staining (0, no staining; 1, low intensity; 2 , medium; 3, high; 4, very high).

cells in the white pulp. Similarly, a small fraction of medular thymic cells with dendritic prolongations showed expression of the transgene. High levels of expression were also detected in a fraction of granulocytes (7-10\%) after indirect immunofluorescence labeling of leukocytes, red cells, and platelets followed by flow cytometry analysis (data not shown).

\section{Levels of Human DAF Expressed by ECs Isolated from Transgenic Rats}

Endothelial cells from heart and lung were isolated from hemizygous $\left(\mathrm{DAF}^{+/-}\right)$and homozygous $\left(\mathrm{DAF}^{+/+}\right)$rats derived from founder 52.2 and from a nontransgenic rat as control. Endothelial cell populations were over $95 \%$ pure as assessed through an anti-rat ICAM-1 and antivWF antibodies. Cell surface expression of hu-
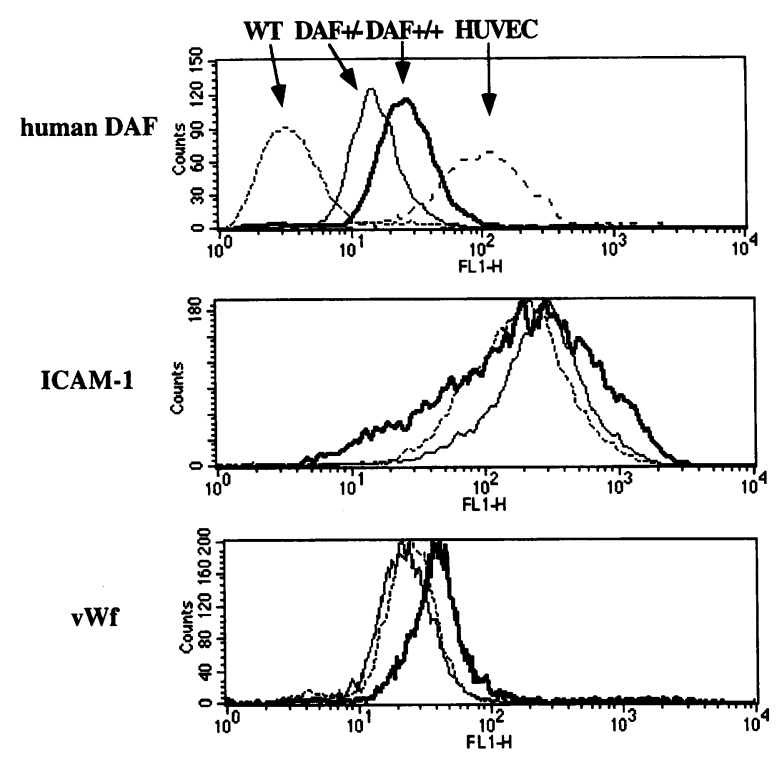

Fig. 4. FACS analysis of human DAF expression by ECs from hemizygous and homozygous transgenic rats. Endothelial cells were isolated from heart of wild-type (WT) and transgenic rats, either hemizygous $\left(\mathrm{DAF}^{+1-}\right)$ or homozygous $\left(\mathrm{DAF}^{+1+}\right)$. Immunostaining was performed using an anti-human DAF MAb to compare levels of DAF expression on ECs. An anti-rat ICAM-1 MAb and anti-human von Willebrand factor (vWf) antibody were used to assess the purity of EC preparations. Fluorescence was measured on 10,000 cells/sample using a FACScalibur. Data are depicted in histograms plotting mean fluorescence intensity (MFI) on a log scale (xaxis) versus cell number ( $y$-axis).

man DAF was investigated by flow cytometry following staining with an anti-DAF MAb. Figure 4 shows that the level of human DAF expressed on cardiac ECs from homozygous $\left(\mathrm{DAF}^{+/+}\right.$) rat was about $50 \%$ the level of DAF on human ECs (HUVEC). As expected, DAF expression was higher in homozygous $\left(\mathrm{DAF}^{+/+}\right)$transgenic rats than in hemizygous $\left(\mathrm{DAF}^{-1+}\right)$ rats. Similar results were obtained with ECs isolated from lung (data not shown).

\section{Protection of DAF-expressing Rat ECs Against Primate Antibodies and C-Mediated Cell Lysis}

The ability of human DAF to confer in vitro protection of rat ECs against primate xenogeneic (anti-rat) antibodies and complement-mediated cell lysis was investigated by incubating ECs isolated from transgenic rats with primate (cynomolgus) sera. Xenoreactivity of human serum for WT or transgenic rats EC was previously determined by flow cytometry analysis. 


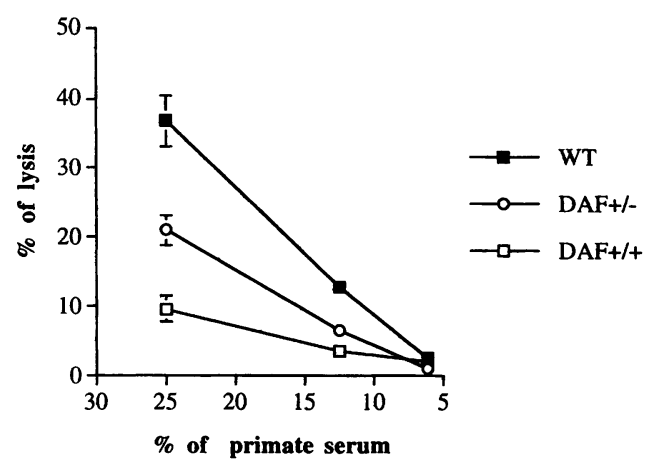

Fig. 5. In vitro protection of ECs isolated from transgenic rats against primate xenogeneic antibodies and complement-mediated cell lysis. Cardiac ECs from wild-type (WT) and transgenic, either hemizygous $\left(\mathrm{DAF}^{+/-}\right)$or homozygous $\left(\mathrm{DAF}^{+/+}\right)$, rats were labeled with $\mathrm{Cr}^{51}$ and incubated for $4 \mathrm{hr}$ at $37^{\circ} \mathrm{C}$ with serial dilutions (from $25 \%$ to $6.12 \%, 50 \mu \mathrm{l} /$ well) of cynomolgus serum. Cell lysis was determined by measuring $\mathrm{Cr}^{51}$ release in culture supernatant as described in Materials and Methods. All experiments were done in triplicate, and the results are expressed as the mean of percent specific lysis \pm SD values. Results are representative of three independent experiments.

Incubation of transgenic (hemizygous or homozygous) rat ECs with purified human antiGal $\alpha \mathrm{l}-3 \mathrm{Gal}$ antibodies showed binding of IgG and IgM XNA that was similar to that of ECs from WT nontransgenic rats (data not shown). Furthermore, ECs from either transgenic or control rats exhibited similar levels of Gal $\alpha 1$ $3 \mathrm{Gal}$ expression as measured by the binding of FITC-labeled Bandera simplicifolia lectin (data not shown). In vitro protection of DAF-expressing rat ECs against antibodies and complement-mediated cell cytotoxicity was measured by incubating rat ECs with serial dilutions of primate (cynomolgus) serum. As shown in Figure 5, primate serum induced a dose-dependent lysis of nontransgenic ECs for serum dilutions ranging between $6 \%$ and $25 \%$. Compared to WT rat ECs, ECs isolated from transgenic rats were protected according to the level of human DAF expressed on the cell surface. When ECs were incubated in the presence of $25 \%$ serum, protection against cell lysis was $74 \pm 6 \%(p<0.05)$ and $43 \pm 4 \%(p<$ $0.05)$ for homozygous and hemizygous, respectively, compared to WT rat ECs (9.6 \pm $0.3 \%, 20.9 \pm 0.1 \%$, and $36.8 \pm 0.1 \%$ of cell lysis for homozygous, hemizygous, and WT, respectively).

Flow cytometry analysis of complement ac-
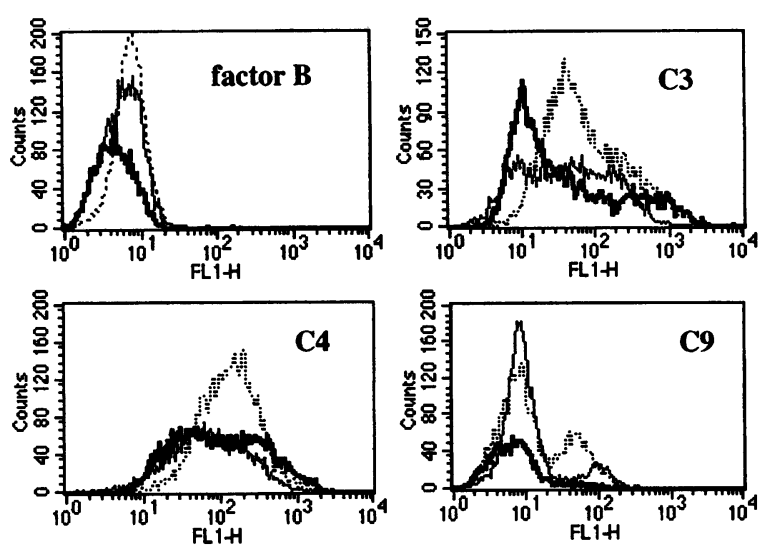

Fig. 6. FACS analysis of in vitro human complement deposition on wild-type versus transgenic rat ECs. Cardiac endothelial cells were isolated from wild-type (dotted line) and transgenic, either $\mathrm{DAF}^{+1-}$ hemizygous (plain line) or $\mathrm{DAF}^{+1+}$ homozygous (bold line), rats. Immunostaining was performed on ECs incubated with human serum (dilution $1 / 10$ ) for $30 \mathrm{~min}$ at $37^{\circ} \mathrm{C}$. After incubation, ECs were washed and then incubated with either an FITC-labeled anti-human C3, C4, or factor B MAb or with an anti-human C5b-9 polyclonal rabbit serum followed by an FITC-labeled anti-rabbit Ab.

tivation on ECs, following incubation with human serum, confirmed the ability of DAF expression to prevent $\mathrm{C} 3$ deposition on ECs since lower amounts of human C3 were detected on transgenic ECs than on WT ECs (Fig. 6). An overall reduction in $\mathrm{C} 9$ was also observed on rat ECs from homozygous transgenic rats whereas no effect of DAF expression was observed for $\mathrm{C} 4$ and factor B deposition.

\section{Ex Vivo Perfusion}

The functional ability of hearts from hemizygous $\mathrm{DAF}^{+1-}$ rats to prevent complement activation was investigated by ex vivo organ perfusion with $15 \%$ human serum. Cardiac function, assessed by cardiac frequence, was monitored over a 60 -min perfusion time (Fig. 7). Our data showed that for DAF-expressing transgenic rats $(n=5)$, heart rate was not affected by serum perfusion and remained stable throughout the experiment. Similarly, perfusion of WT rat hearts with heat-inactivated serum $(n=5)$ showed normal cardiac function (data not shown). In contrast, cardiac function failed rapidly after perfusion of WT rat hearts with XNA and complement-containing human serum and stoped at $11.2 \pm 1.7 \mathrm{~min}$ $(n=5)$. 


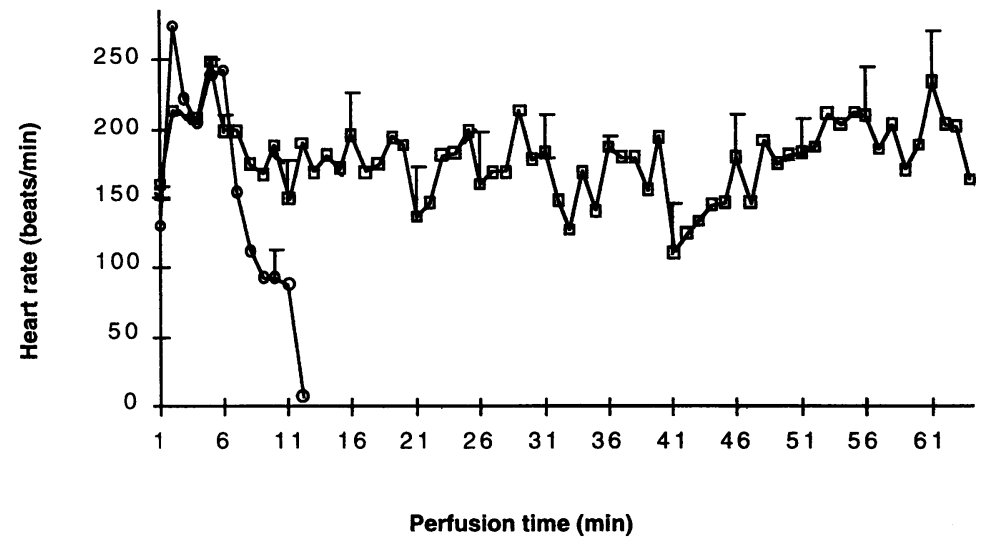

Fig. 7. Cardiac function of transgenic rat hearts during ex vivo perfusion with human serum. Hearts from wild-type (circles) ( $n=5$ ) or $\mathrm{DAF}^{+1-}$ hemizygous transgenic (squares) $(n=5)$ rats were perfused with $15 \%$ human serum for 60 min using a Langendorff apparatus. Heart rate (y-axis) was monitored every min ( $\mathrm{x}$-axis) throughout the experiment. Every point of analysis corresponds to the mean value of five experiments and SD is shown for values taken every $5 \mathrm{~min}$.
Xenotransplantation of DAF ${ }^{+}$Transgenic Rat Hearts into Primates

Transplantation of transgenic hearts was performed on cynomolgus to assess whether the expression levels of human DAF on ECs were sufficient to prevent HAR. We previously demonstrated that in this discordant combination, cardiac xenografts were hyperacutely rejected in $5.5 \pm 1.4 \mathrm{~min}$ following binding of primate $\mathrm{XNA}$ and activation of complement through the classical pathway (19). To overcome a potential variability in xenoreactivity of primate recipients, hemizygous and homozygous transgenic hearts were grafted in each femoral vessel from the same recipient. Survival times of transplanted transgenic hearts are reported in Table 1 . These results show that levels of DAF expression were correlated in vivo with the degree of protection against XNA and complement-mediated HAR. Nevertheless, protection for homozygous hearts compared to that for hemizygous hearts was higher than expected from in vitro experiments (Figs. 5 and 6). Indeed, for hearts from hemizygous rats, rejection was delayed from 5 min to $15.5 \mathrm{~min}(n=4) \quad(p<0.05$ compared to WT hearts), whereas cardiac xenograft survival was up to $>4.5 \mathrm{hr}$ for homozygous rats $(n=2)(p<$ 0.05 compared to WT or hemizygous transgenic hearts). Because the time of rejection could only be assessed on anesthetized primates, only a minimal estimation can be given here.

Histology of $\mathrm{DAF}^{+/-}$rejected hearts, collected at the time of rejection, showed no significant evidence of edema or hemorrage but showed microthrombosis, as previously described for nontransgenic rats (19). Nevertheless, differences were observed among tissue samples according to survival time. Indeed, a transplant that survived for 28 min exhibited a significant PMN infiltration in the interstitium and binding

Table 1. Survival time of heterotopic cardiac xenografts of transgenic rat hearts (hemizygous DAF ${ }^{+\prime-}$ or homozygous $\mathrm{DAF}^{+/+}$) transplanted into cynomolgus recipients

\begin{tabular}{|c|c|c|c|}
\hline & \multicolumn{3}{|c|}{ Rat donor } \\
\hline & wild type & Hemizygous $\left(\mathrm{DAF}^{+1-}\right.$ ) & Homozygous $\left(\mathrm{DAF}^{+/+}\right.$) \\
\hline Survival time & $\begin{array}{c}5.5 \pm 1.4 \mathrm{~min} \\
(n=10)\end{array}$ & $\begin{array}{c}15.2 \pm 7.4 \mathrm{~min}^{*} \\
(10,11,12,28 \mathrm{~min}) \\
(n=4)\end{array}$ & $\begin{array}{c}>1.5 \mathrm{hr}^{\star * a} \\
>4.5 \mathrm{hr}^{\star * a} \\
(n=2)\end{array}$ \\
\hline \multicolumn{4}{|c|}{ 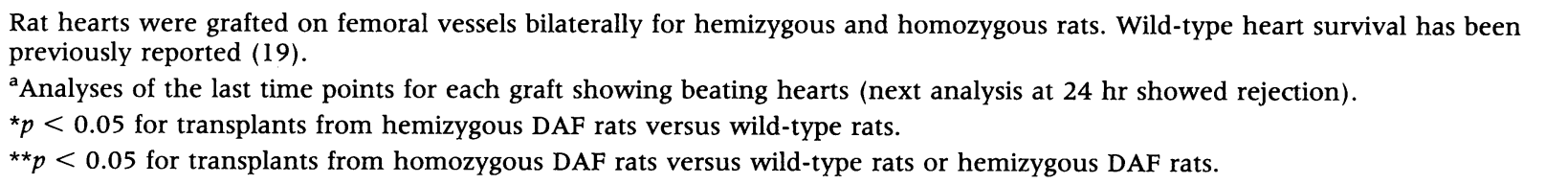 } \\
\hline
\end{tabular}




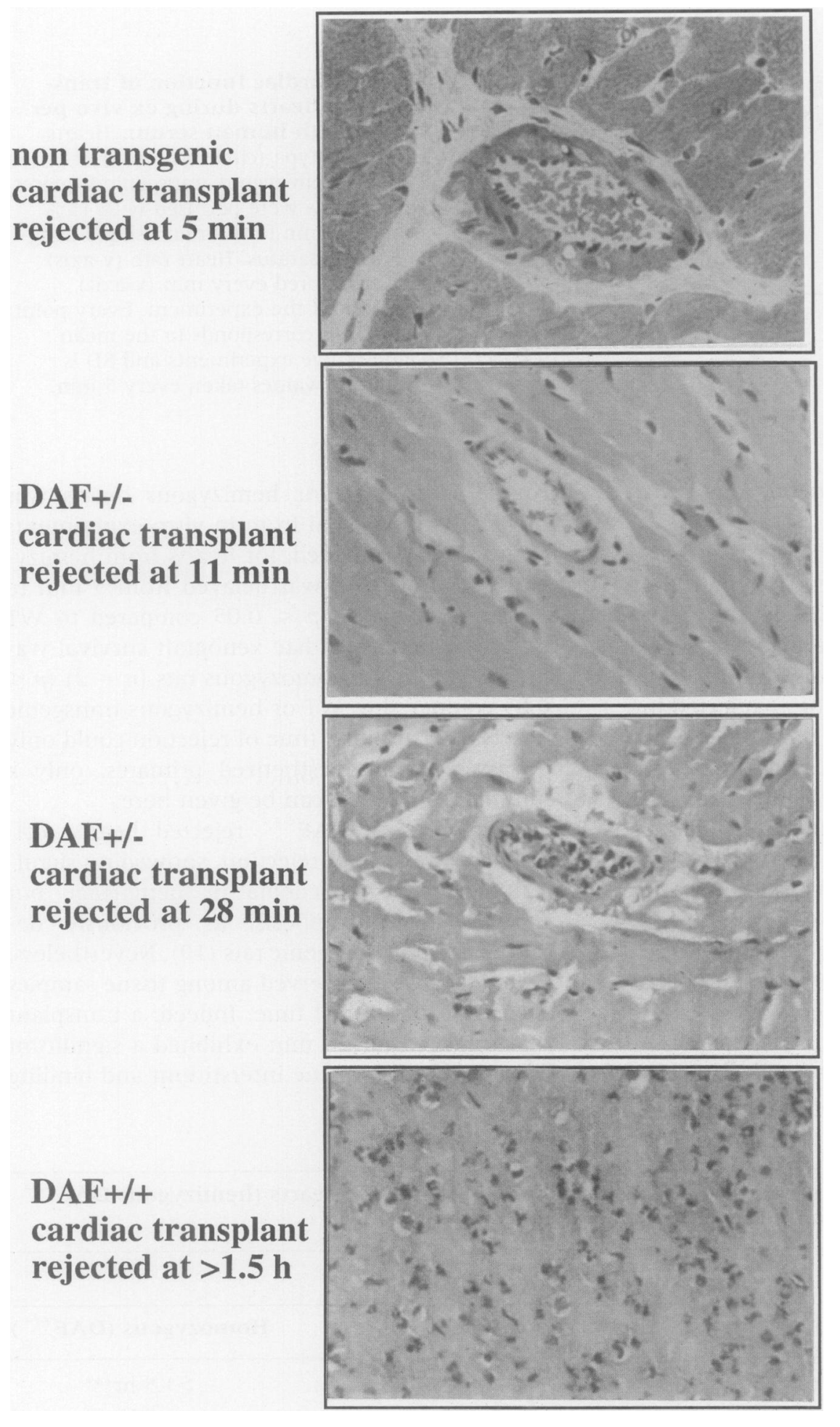

Fig. 8. Histological analysis of DAF-expressing cardiac xenografts. Hearts were collected at the following times of rejection: $5 \mathrm{~min}$ for wild type, and $11 \mathrm{~min}$ and $28 \mathrm{~min}$ for $\mathrm{DAF}^{+1-}$ transgenic rats, and after rejection for $\mathrm{DAF}^{+\prime+}$ transgenic rats. Tissue sections were counterstained with hematoxylin-eosin (magnification, $\times 400$ ). to the endothelium of blood vessels compared to cardiac xenograft rejected at 11 min (Fig. 8). Biopsies from DAF homozygous heart transplants also showed an abundant leukocyte infiltration that was mostly composed of PMN, but also include a small fraction of monocytes. Vas- cular damage, focal necrotic lesions of myocardium, and interstitial hemorrhage were also observed.

Immunohistochemical analysis revealed deposition along endothelial surfaces of recipient IgG, IgM, and complement components of the 
Table 2. Immunohistochemical analysis of cardiac xenografts for human Ig and complement deposition

\begin{tabular}{|c|c|c|c|c|c|c|c|c|}
\hline Rats & $\underset{\text { DAF }}{\text { Human }}$ & $\mathbf{v W f}$ & $\begin{array}{l}\text { Human } \\
\text { IgG }\end{array}$ & $\underset{\text { IgM }}{\text { Human }}$ & C3 & C4 & C9 & $\begin{array}{c}\text { Factor } \\
\text { B }\end{array}$ \\
\hline $\begin{array}{c}\text { Ungrafted wild } \\
\text { type }(n=3)\end{array}$ & - & ++ & - & - & - & - & - & - \\
\hline Wild type $(n=3)$ & - & +++ & ++ & + & ++ & $+1++$ & ++ & - \\
\hline $\begin{array}{l}\mathrm{DAF}^{+1-} \text { transgenic } \\
\quad(n=3)\end{array}$ & +++ & +++ & ++ & + & + & + & $-1+$ & - \\
\hline $\begin{array}{l}\mathrm{DAF}^{+1+} \text { transgenic } \\
\quad(n=2)\end{array}$ & ++++ & +++ & ++ & + & + & + & $+1-$ & - \\
\hline
\end{tabular}

Immunostaining of xenograft cryosections was performed as described in Materials and Methods. Results are expressed as a mean of experiments performed on two $\left(\mathrm{DAF}^{+1+}\right.$ transgenics) or three (ungrafted, wild-type, and $\mathrm{DAF}^{+1-}$ transgenic) animals.

- , no staining; + , low intensity; ++ , medium intensity; +++ , high intensity; ++++ , very high intensity.

classical but not the alternative pathway (Table 2). Less C3 and C9 fragment deposition was observed on transgenic tissues than on that of rejected organs from WT rats.

\section{Discussion}

Genetically engineered animals offer a unique opportunity for using donor animal organs for clinical transplantation. Transgenic pigs, which express molecules that could control immunological events associated with xenograft rejection, could be the first suitable source of these transplants. Transgenic mice are useful models for the analysis of promoter tissue specificity and transgene expression levels $(24,25)$. However, there are no mouse models available for the study of transplantation of vascularized organs into primates. Investigation of transgenic or knockout mouse models (although restricted to ex vivo perfusion experiments) can be informative for several aspects of transgene function, but they do not allow analysis of the broad range of humoral and cellular interactions between graft and recipient that operate in vivo $(25,26)$. Therefore, we have postulated that production of transgenic rats, which can be used for xenotransplantation into primates (19), could provide a useful in vivo model to test the benefits of genetic engineering interventions in xenotransplantation (22). The first step in validating this model was to demonstrate that endotheliumdirected expression of human DAF in rat organs can delay xenograft HAR.
Transgene distribution in transgenic organs is a major concern for xenotransplantation. For membrane-bound proteins such as CRPs, transgenes should be expressed at least on ECs (the first target of XNA binding and complement activation), since few other cell types in the rat (and also the pig) express the Gal $\alpha 1-3 \mathrm{Gal}$ epitope (7). Our data show that endothelium-restricted transgene expression can be obtained in transgenic rats by using part of the human ICAM-2 gene promoter, and that tissue distribution of transgene expression in transgenic rats is almost identical to transgene expression in lines of transgenic mice (18).

The ability of human DAF to overcome primate XNA and complement-mediated rat cell lysis was demonstrated in vitro on isolated transgenic rat ECs. The data generated from this study provided in vivo confirmation of our previous in vitro experiments performed on transfected rat ECs, which demonstrated the ability of human DAF and CD59 to protect rat ECs from primate complement-mediated damage (20). Cardiac-derived ECs from rats homozygous for DAF expressed around $50 \%$ of the DAF levels observed in HUVECs. However, compared with other human cells, HUVECs express very high levels of DAF $\left(3 \times 10^{5}\right.$ molecules per cell compared with $8 \times 10^{4}$ molecules per cell for human leukocytes) $(27,28)$. DAF levels on human ECs derived from organs have not yet been reported.

Because ECs from transgenic rats homozygous for DAF were more resistant to primate serum-mediated damage than ECs from rats hemizygous for DAF, in vitro inhibition of com- 
plement-dependent EC lysis and complement fragment deposition was said to be correlated with DAF levels. In ex vivo perfusion experiments, hemizygous DAF hearts were very efficiently protected from complement-mediated damage from $15 \%$ human serum, but showed only limited survival in vivo. Although a statistically significant improvement of graft survival time for hemizygous rats was observed ( 5 min for WT rats versus $15 \mathrm{~min}$ for hemizygous DAF rats), this has little relevance in vivo. The difference in in vivo versus ex vivo survival time is probably due to higher XNA and complement concentrations in vivo and the contribution of recipient blood cells absent from the ex vivo experiments. In contrast, the prolongation of xenograft survival to a minimal period of several hours $(>1.5$ hr to $4.5 \mathrm{hr}$ ) in homozygous DAF rats indicates that this level of transgene expression is sufficient to delay HAR in the absence of XNA depletion or immunosuppression of the recipient.

In some previous reports on the generation of transgenic animals for CRPs, levels of transgene expression have been quantified on ECs. Diamond et al. showed that expression of CD59 on aortic ECs from transgenic pigs reached $20 \%$ of the levels of HUVEC, conferred $50 \%$ protection against complement-mediated EC lysis in vitro, and compared with the controls, slightly prolonged xenograft survival $(0.5 \mathrm{hr}$ and $1 \mathrm{hr}$ versus $2.2 \mathrm{hr}$ and $3 \mathrm{hr}$, respectively) (29). Byrne et al. showed that aortic ECs expressed CD59 and DAF levels that were $67 \%$ and $45 \%$ of HUVEC levels, respectively, and had a 3- to 5-fold increased resistance against complement-mediated lysis in vitro (14). Xenografts were shown to have variable survival periods compared with controls (range $6 \mathrm{hr}$ to 5 days versus $0.5 \mathrm{hr}$ to 1 hr, respectively), and survival could be prolonged by depletion of xenoreactive antibodies (16). Importantly, in these transplantation trials, recipients also received extensive immunosuppressive and anti-coagulant treatment $(14,16,29)$. Taken together these studies suggest that although moderate levels of DAF transgene expression (20$40 \%$ of HUVEC levels) are able to confer protection against HAR in conditions in which complement or antibodies are limited (in vitro or ex vivo perfusion), a minimal threshold of protection in vivo requires DAF levels that are at least close to $50 \%$ of HUVEC levels. In agreement with this hypothesis, Cozzi et al. reported that transgenic hearts, which expressed DAF at levels several-fold higher than HUVECs (13), showed effective protection during ex vivo perfusion with human blood, and xeno- graft survival was considerably prolonged ( 5.1 days versus 1.6 days in controls) in the absence of any other treatment (15). However, these transgenic organs, even in immunosuppressed recipients, have been almost invariably rejected by AVR $(30,31)$.

Nontransgenic rat hearts transplanted into primates have been rejected with a histological pattern of HAR showing endothelial cell damage, platelet microthrombi, and little PMN vascular accumulation (19). In contrast, rat hearts transplanted into primates treated with cobra venom factor (19) or DAF transgenic hearts that have survived transplantation for at least $28 \mathrm{~min}$ have been rejected, with a histological pattern of AVR showing extensive thrombosis, leukocyte accumulation (mainly PMN) in the vessels and tissues, edema, and hemorrhage. Furthermore, increased levels of DAF in transplanted organs (from homozygous and hemizygous DAF transgenic rats) result in longer periods of graft survival that correlate with progressive PMN infiltration, hemorrhage, and focal myocardial necrosis. Similarly, AVR is the most common result of xenotransplantation between discordant species (guinea pig-to-rat or pig-to-primate) after XNA depletion, complement inactivation of recipients, or transplantation of CRP transgenic organs $(4,10,12,14-16,32,33)$. Although AVR in these models share common pathological features (hemorrhage, edema, and presence of leukocytes), they also show differences in the type of infiltrating leukocytes. In transplant combinations involving rats as recipients, mononuclear cell infiltrates predominate $(33,34)$, whereas combinations involving primates as recipients (especially when the primates do not receive immunosuppressive drugs) show leukocyte infiltrates with mononuclear cells and a high proportion of PMN $(4,15)$.

Taken together, our results demonstrate that a moderate level of human DAF expression on rat endothelium prolongs xenograft survival beyond HAR and that the PMN infiltration, hemorrhage, and focal myocardial necrosis associated with AVR in pig-to-primate transplants are also present in rat-to-primate transplants. It is likely that higher levels of DAF expression are required to further improve xenograft survival, or that other factors in addition to complement (such as XNA binding to ECs and mechanisms such as coagulation and EC activation) must be controlled to prevent xenograft AVR.

In conclusion, xenotransplantation of transgenic organs expressing CRPs, from either pig or 
rat, prevents HAR but not the development of AVR, even when immunosuppressed primates are used as recipients (14-16,30,31). Therefore, there is an urgent need to express new transgenes to protect xenografts and decrease the side effects of immunosuppression. These transgenes should probably be aimed at decreasing Gal $\alpha 1$ $3 \mathrm{Gal}$ expression or inhibiting coagulation and tissue infiltration by leukocytes. The development of transgenic rats represents a more rapid alternative than the production of transgenic pigs for testing the usefulness of new strategies and allows an easier analysis of mechanism of action. In this regard, the backcross of transgenic rats expressing DAF to prevent HAR, and the backcross of rats expressing Fas ligand in the endothelium (35) that could inhibit PMN adherence to endothelium (36) may facilitate analysis of the role of early leukocyte infiltration in AVR.

\section{Acknowledgments}

The authors thank Dr. J.-F. Bouhours for providing purified human anti-Gal $\alpha \mathrm{l}-3 \mathrm{Gal} \mathrm{Ab}$ and $\mathrm{Dr}$. A. P. Dalmasso for providing anti-human C5b-9 serum. They also thank Claire Usal, Valia Proust and Emmanuel Merieau for expert animal care. This work was supported in part by EEC grants (Biotech BIO4-CT97-2242 and Biomed2 BMM4CT98-327) from the Fondation de Transplantation and the Fondation Transvie.

\section{References}

1. Platt JL. (1998) New directions for organ transplantation. Nature 392: 11-17.

2. Galili U. (1993) Interaction of the natural anti-Gal antibody with $\alpha$-galactosyl epitopes: A major obstacle for xenotransplantation in humans. Immunol. Today 14: 480-482.

3. Sandrin MS, Vaughan HA, Dabkowski PL, McKenzie IF. (1993) Anti-pig IgM antibodies in human serum react predominantly with Gal(alpha 1-3)Gal epitopes. Proc. Natl. Acad. Sci. U.S.A. 90: 11391-11395.

4. Platt JL, Fischel RJ, Matas AJ, Reif SA, Bolman RM, Bach FH. (1991) Immunopathology of hyperacute xenograft rejection in a swine-to-primate model. Transplantation 52: 214-220.

5. Dalmasso AP, Vercellotti GM, Fischel RJ, MortonBolman R, Bach FH, Platt JL. (1992) Mechanism of complement activation in the hyperacute rejection of porcine organs transplanted into primate recipients. Am. J. Pathol. 140: 1157-1 166.

6. Borche L, Thibaudeau K, Navenot J-M, Soulillou
J-P, Blanchard D. (1994) Cytolytic effect of human anti-Gal IgM and complement on porcine endothelial cells: A kinetic analysis. Xenotransplantation 1: 125-131.

7. Azimzadeh A, Wolf $P$, Thibaudeau $K$, Cinqualbre J, Soulillou JP, Anegon I. (1997) Comparative study of target antigens for primate xenoreactive natural antibodies in pig and rat endothelial cells. Transplantation 64: 1166-1174.

8. Leventhal JR, John R, Fryer JP, et al. (1995) Removal of baboon and human antiporcine IgG and IgM natural antibodies by immunoadsorption. Results of in vitro and in vivo studies. Transplantation 59: 294-300.

9. Shinkel TA, Chen CG, Salvaris E, et al. (1997) Changes in cell surface glycosylation in alpha1,3galactosyltransferase knockout and alphal,2-fucosyltransferase transgenic mice. Transplantation 64: 197-204.

10. Pruitt SK, Kirk AD, Bollinger RR, et al. (1994) The effect of soluble complement receptor type 1 on hyperacute rejection of porcine xenografts. Transplantation 57: 363-370.

11. Fodor WL, Williams BL, Matis LA, et al. (1994) Expression of a functional human complement inhibitor in a transgenic pig as a model for the prevention of xenogeneic hyperacute organ rejection. Proc. Natl. Acad. Sci. U.S.A. 91: 11153-11157.

12. McCurry KR, Kooyman DL, Alvarado CG, et al. (1995) Human complement regulatory proteins protect swine-to-primate cardiac xenografts from humoral injury. Nat. Med. 1: 423-427.

13. Cozzi E, Tucker AW, Langford GA, et al. (1997) Characterization of pigs transgenic for human decay-accelerating factor. Transplantation 63: 13831392.

14. Byrne GW, McCurry KR, Martin MJ, McClellan S, Platt JL, Logan JS. (1997) Transgenic pigs expressing human CD59 and decay-accelerating factor produce an intrinsic barrier to complement mediated damage. Transplantation 63: 149-155.

15. Cozzi E, Yannoutsos N, Langford GA, PinoChalvez G, Wallwork J, White DJG. (1997) Effect of transgenic expression of human decay accelerating factor on the inhibition of hyperacute rejection of pig organs. In: Cooper DKC, Kemp E, Platt JL, White DJ (eds). Xenotransplantation: The Transplantation of Organs and Tissues Between Species. Springer-Verlag, Berlin, p. 665-682.

16. Lin SS, Weidner BC, Byrne GW, et al. (1998) The role of antibodies in acute vascular rejection of pig-to-baboon cardiac transplants. J. Clin. Invest. 101: 1745-1756.

17. Byrne GW, McCurry KR, Kagan D, et al. (1995) Protection of xenogeneic cardiac endothelium from human complement by expression of CD59 or DAF in transgenic mice. Transplantation 60: 1149-1156.

18. Cowan PJ, Shinkel TA, Witort EJ, Barlow H, Pearse MJ, D'Apice AJ. (1996) Targeting expres- 
sion to endothelial cells in transgenic mice using the human intercellular adhesion molecule 2 promoter. Transplantation 62: 155-160.

19. Azimzadeh A, Wolf P, Dalmasso AP, et al. (1996) Assessment of hyperacute rejection in a rat-toprimate cardiac xenograft model. Transplantation 61: 1305-1313.

20. Charreau B, Cassard A, Tesson L, et al. (1994) Protection of rat endothelial cells from primate complement-mediated lysis by expression of human CD59 and/or decay-accelerating factor. Transplantation 58: 1222-1229.

21. Cowan PJ, Tsang D, Pedic CM, et al. (1998) The human ICAM-2 promoter is endothelial cell-specific in vitro and in vivo and contains critical Spl and GATA binding sites. J. Biol. Chem. 273: $11737-$ 11744.

22. Charreau B, Tesson L, Soulillou J-P, Pourcel C, Anegon I. (1996) Transgenesis in rats: Technical aspects and models. Transgenic Res. 5: 223-234.

23. Jaffe EA, Nachman RL, Becker CG, Minick CR. (1973) Culture of human endothelial cells derived from umbilical veins. J. Clin. Invest. 52: 2745-2756.

24. van Denderen BJ, Pearse MJ, Katerelos M, et al. (1996) Expression of functional decay-accelerating factor (CD55) in transgenic mice protects against human complement-mediated attack. Transplantation 61: 582-588.

25. Cowan PJ, Chen CG, Shinkel TA, et al. (1998) Knock-out of alphal,3-galactosyltransferase or expression of alphal,2-fucosyltransferase further protects CD55- and CD59-expressing mouse hearts in an ex vivo model of xenograft rejection. Transplantation 65: 1599-1604.

26. Cowan PJ, Somerville C, Shinkel TA, et al. (1998) High level endothelial expression of human CD59 in an ex vivo model of xenograft rejection prolongs heart function. Transplantation 65: 826-831.

27. Nicholson-Weller A, Burge J, Fearon DT, Weller PF, Austen KF. (1982) Isolation of a human eryth- rocyte membrane glycoprotein with decay accelerating activity for $\mathrm{C} 3$ convertases of the complement system. J. Immunol. 129: 184-189.

28. Brooimans RA, van Wieringen PA, van Es LA, Daha MR. (1992) Relative roles of decay-accelerating factor, membrane cofactor protein, and CD59 in the protection of human endothelial cells against complement-mediated lysis. Eur. J. Immunol. 22: 3135-3140.

29. Diamond LE, McCurry KR, Martin MJ, et al. (1996) Characterization of transgenic pigs expressing functionally active human CD59 on cardiac endothelium. Transplantation 61: 1241-1249.

30. Schmoeckel M, Bhatti FN, Zaidi A, et al. (1998) Orthotopic heart transplantation in a transgenic pig-to-primate model. Transplantation 65: 15701577.

31. Zaidi A, Schmoeckel M, Bhatti F, et al. (1998) Life-supporting pig-to-primate renal xenotransplantation using genetically modified donors. Transplantation 65: 1584-1590.

32. Leventhal JR, Matas AJ, Sun LH, et al. (1993) The immunopathology of cardiac xenograft rejection in the guinea pig-to-rat model. Transplantation 56: 1-8.

33. Blakely ML, Van Der Werf W, Berndt MC, Dalmasso AP, Bach FH, Hancock WW. (1994) Activation of intragraft endothelial and mononuclear cells during discordant xenograft rejection. Transplantation 58: 1059-1066.

34. Brouard S, Vanhove B, Gagne K, et al. (1999) T-cell repertoire of vascularized xenograft. $\mathrm{J}$. Immunol. 162: 3367-3377.

35. Tesson L, Charreau B, Ménoret S, Soulillou J-P, Anegon I. (1999) Endothelium-specific expression of Fas ligand on transgenic rats. Transplant. Proc. 31: 1533-1534.

36. Sata M, Walsh K. (1998) TNF $\alpha$ regulation of Fas ligand expression on the vascular endothelium modulates leukocyte extravasation. Nat. Med. 4: 415-420. 